\title{
Expanding ecological appropriation approach: Solar space method and a case study in Yangzhou city, East China
}

\author{
Dan $\mathrm{Hu}^{\mathrm{a}, *}$, Ru-Song Wang ${ }^{\mathrm{a}}$, Kam-Peng Lei ${ }^{\mathrm{b}}$, Feng $\mathrm{Li}^{\mathrm{a}}$, Zhen Wang ${ }^{\mathrm{a}}$, Ben-Nan Wang ${ }^{\mathrm{a}}$ \\ ${ }^{a}$ State Key Laboratory of Urban E' Regional Ecology, Research Center for Eco-Environmental Sciences, Chinese Academy of Sciences, Beijing, 100085, China \\ ${ }^{\mathrm{b}}$ Faculty of Science and Technology, University of Macao, MSAR, China
}

\section{A R T I C L E I N F O}

\section{Article history:}

Received 4 February 2009

Received in revised form 31 August 2009

Accepted 7 September 2009

Available online 9 October 2009

\section{Keywords:}

Solar space method (SS)

Ecological footprint (EF)

Emergy

Characteristics of ecosystems appropriation

Yangzhou city

Eastern China

\begin{abstract}
A B S T R A C T
In this paper, the authors made an attempt to measure appropriation of ecosystems more reasonably and effectively based on examining the advantages and disadvantages of emergy analysis and ecological footprint. By combining emergy analysis with ecological footprint (EF) in terms of spatial equivalent of energy productivity, a new method of solar space (SS) and its calculating framework was proposed, and some necessary parameters for this method of analysis were calculated. A case study was followed under this calculating framework for Yangzhou city, Jiangsu province, Eastern China, using the data of the year 2000. The main results are as follows: (1) The ecological space in Yangzhou city includes earth surface space and solar space, and their demands were bigger than their supply. In the year of 2000, the earth surface space had an absolute deficit of 2.3063E-02 Ga-ha per capita (global hectares), and the solar space had an absolute deficit of 1.4944E-04 Sa-ha per capita (solar hectares). (2) There was a relative ecological deficit of $3.68 \%$ in earth surface space, and that of $154.86 \%$ in solar space. (3) Only freshwater areas and built-up areas were in a state of surplus, and there was a relative ecological surplus of $82.66 \%$ for freshwater areas, being greater than that for built-up areas. (4) The ranking of absolute ecological deficit in a descending order was as follows: solar space $>$ arable land $>$ pasture $>$ forest $>$ marine area $>$ garden land, while the relative ecological deficit was the following: solar space $>$ pasture land $>$ forest land $>$ arable land $>$ garden land, except marine areas.

A qualitative comparison of methodology was made between solar space method and ecological footprint according to their capability to describe the temporal-spatial characteristics of ecosystems appropriation. Moreover, a quantitative comparison was also conducted to show their differences in applicability to the assessment of ecosystems appropriation. It was shown that the calculating results from solar space method were bigger than that from ecological footprint because the former supplemented additional items of appropriation omitted by the later and included some new items of indirect appropriation that were excluded by the later. It is found that the new measure of solar space operates well as an indicator of the city's appropriation to ecosystems.
\end{abstract}

(c) 2009 Elsevier B.V. All rights reserved.

\section{Introduction}

Any life changes its surrounding environment, and human beings are no exception. Up to the present, approximately half of the global surface has undergone changes caused by human activities of appropriation (Postel et al., 1996; Vitousek et al., 1986, 1997).

In recent years, ecosystems appropriation has gradually become one of the hot topics in measuring the impacts of humans on its surrounding ecosystems. Since the 1990s of last century, inspired by Vitousek's pioneering work in analyzing the appro-

\footnotetext{
* Corresponding author. Tel.: +86 10 62849199; fax: +86 1062943807 .

E-mail addresses: hudan@rcees.ac.cn, hrcees@vip.sina.com (D. Hu).
}

priation of bio-physical quantity of photosynthetic products by humans, Wackernagel and Rees accepted the former ideas of describing ecosystems appropriation by area (Odum, 1975, 1989; Jansson and Zucchetto, 1978), and proposed the concept of ecological footprint (Wackernagel and Rees, 1996; Wackernagel et al., 1999a, 1999b; Rees, 2000; Folke et al., 1997). Since then, many papers on this topic have been published, and immediately attracted great attention from many scholars (Haberl, 1997; Haberl et al., 2004; Jansson et al., 1999; Van den Bergh and Verbruggen, 1999; Simmons and Lewis, 2000; Lenzen and Murray, 2001; Haberl et al., 2001; Ferng, 2001). According to the trends within this field of research, progress was mainly made in the two aspects: (i) research on the ecosystems appropriation in terms of bio-physical quantity of flows (e.g. photosynthetic products); (ii) analyses of ecosystems appropriation based on bio-physical space 
(e.g. earth surface) which was typically represented by ecological footprint method (abbreviated as EF hereafter). This approach has its advantages: (1) a good bio-physical basis for analyzing human-ecosystem interactions, and (2) a good spatial-based measure of ecosystems appropriation. However, there exists some limitations or defects in EF analysis: (1) The use of cumulative weights as equivalent and yield factors is based on a large amount of assumptions such as a high substitutability among man-made, human and natural capitals, and neglects the differences among different types of land such as arable land and built-up areas, only reflecting the difference of bio-productivity for various types of land, but not reflecting other technological, and socio-economical factors that influence land productivity (Van den Bergh and Verbruggen, 1999; Ayres, 2000; Lenzen and Murray, 2001). (2) The limited applicability: EF excludes both appropriation of non bio-productive areas (e.g. ground water, some natural energy) and various indirect appropriations, and the concept of fossil energy land excessively emphasizes forest used as carbon sink that in fact serves as both carbon source and carbon sink, which is only one of many solutions to absorb discharged $\mathrm{CO}_{2}$ in a given period of time, there are also other practical and promising solutions. In addition, EF exclusively focuses on carbon dioxide, neglecting many other greenhouse gases for calculation (e.g. ozone, methane). The EF concept is too simple to describe completely the diversity of ecosystems appropriation (Moffatt, 2000; Rees, 2000). (3) EF is just a static analysis of stock, and lacks dynamic analysis of fluxes, so it cannot reflect the process of ecosystems appropriation in a period of time (Moffatt, 2000; Lenzen and Murray, 2001). (4) The inaccurateness in calculation: it excessively simplified the relationships between nature and humans, and ignored their complex dynamic behaviors such as multi-scale hierarchy, resilience, non-linearity, discontinuity and uncertainty, etc., which universally occurs in EF calculations (Anand and Li, 2001; Li et al., 2004; Makarieva et al., 2004, 2005, 2006, 2008a, 2008b). Therefore, it has very low predictability (Moffatt, 2000; Rees, 2000).

In these years, efforts have been made to modify EF method, which mainly include: (1) to add footprint components of aquatic products from freshwater areas into calculation (Jansson et al., 1999; Wackernagel et al., 1999a, 2005; Haberl et al., 2001); (2) to introduce input-output analysis into EF calculation framework so as to reflect processes of appropriation (Bicknell et al., 1998; Ferng, 2001), and make static EF analysis become a dynamic time-series analysis of EF (Haberl et al., 2001); (3) to use component-based calculation of footprint to make results more clear, though it is influenced by the availability of data (Simmons and Lewis, 2000); (4) to expand the applicability to include other types of land, for example, analyzing appropriation in terms of land disturbance by human activities instead of land bio-productivity (Lenzen and Murray, 2001).

Emergy analysis is a useful approach for assessing energy processes of human-ecosystem interactions, and has been widely applied in various fields of ecological research (Odum, 1996). The characteristics of emergy approach are: (1) very extensive applicability, energy is necessarily used for ecosystem processes, and emergy becomes a good measure of equivalence for indicating the relations among various types of energy and material fluxes. (2) Emergy analysis may connect human consumption with natural ecosystems and include all the direct and indirect consumption of energy by humans. (3) Emergy analysis is a process-based dynamic approach. But emergy analysis also has its disadvantages: (1) the calculation of emergy is subject to the parameters of transformity that depends upon the context of ecosystems. (2) Emergy analysis is energy-based, neglecting the characteristics of masses and informative fluxes. (3) The theory of emergy has an assumption that all the energies driving processes of ecosystem come from the sun, in fact, many ecosystems are not driven exclusively by solar energy, especially human or artificial ecosystems.

As discussed above, the main weaknesses of EF approach are its static analysis framework and its limited applicability. In contrast, emergy approach has just high applicability and is a process-based analysis of energy. In addition, EF approach is spatial-based and energy is the largest component in EF, so these two approaches can supplement each other. In this research, the authors firstly combined emergy analysis with ecological footprint (EF) in terms of spatial equivalent of energy productivity to establish a new method of solar space for measuring ecosystems appropriation. Then, the calculating procedure for the method of solar space was proposed. A case study of Yangzhou city, Jiangsu province, Eastern China in the year of 2000 was followed using this new analysis method, and some significant research results have been achieved. Finally, a methodological comparison was done between the two approaches of solar space and EF to present their capability to assess the temporal-spatial dynamics of ecosystems appropriation.

\section{Solar space method}

Based on the idea of equivalent of energy productivity, we integrated analysis of energy processes in the emergy approach (Odum, 1996) into the analysis of spatial composition in EF approach, and proposed the concept of solar space that is different from the concept "fossil energy land" in EF approach. So a new method for ecosystems appropriation analysis might be established which is called as solar space method (abbreviated as SS hereafter). Its calculation framework is discussed in the following.

\subsection{The measure of space appropriation for solar space method (SS)}

Solar space refers to the spatial equivalent of solar energy directly and indirectly required by a specific human settlement on the globe within a period of time. Usually, it may be expressed as a spatial amount of the sun in terms of volume or area. In this research, we use the area of solar surface in a unit of solar hectare, abbreviated as Sa-ha. Correspondingly, the area of earth surface space is denoted in a unit of global hectare, abbreviated as Ga-ha.

The sun is now in the mid-period of its development, and the energy release of its outer layer is relatively steady. The released quantity of solar energy per unit of its surface may be defined as solar space coefficient (SSC), with a unit of $\mathrm{Gj} / \mathrm{Sa}$-ha. As solar rays travel from the sun to the earth surface, the solar energy available in different regions on the earth is changeable due to the variation of radiation angles. Meanwhile, its energy density is gradually lessened for the interactions of atmosphere physical-chemical processes (like absorption, reflection, etc.). So the characteristics of solar radiation on the earth surface are obviously different from that on the surface of the sun. It is called as the solar space of the earth surface (ESS), also with a unit of $\mathrm{Gj} / \mathrm{Ga}$-ha. If not specified, the earth surface space in this article is generally expressed in Ga-ha, and the solar space in Sa-ha or Ga-ha (in terms of energy space on the earth) in a given year.

\subsection{The calculating parameters for SS}

\subsubsection{Re-adjusting equivalent and yield factors}

Bio-productivity is a key to calculate equivalent and yield factors in the conventional EF analysis. After adopting a new measure of solar space, we need re-adjust these factors according to the quantitative equivalent of energy productivity for different types of space. Usually, the calculation of these factors can still be done by employing the available data of global bio-productivity originally proposed by Wackernagel (Wackernagel et al., 1999a, $1999 \mathrm{~b})$. In addition, the conventional classification system of land 
in EF analysis needs to be modified, a modified spatial classification system may be established to include solar space, freshwater and garden land (garden land is separated from arable land because of its obviously different bio-productivity and ecological services). Thus, there are totally eight types of space in the modified classification system. Except for solar space, the other seven categories of space are as follows:

(1) Arable land: the land supplying humans with agricultural products like grains and oil, and other ecological services like landscape aesthetics and ecological tourisms. It is usually believed as the most bio-productive land on the earth surface. The arable land per capita is only 0.25 ha at present in the world, and its equivalent factor has adjusted to be 2.82 .

(2) Freshwater area: it is a type of important land for supplying humans with many kinds of ecological services such as tapwater, aquatic products, aquatic life's habitats, absorption of pollution, recreation and aesthetics value, etc. its equivalent factor has adjusted to be 0.43 .

(3) Garden land: a type of land for supplying agricultural products like vegetables, tea and fruits, etc. It also provides many other ecological services such as regulation of micro-climate and aesthetics of landscape. Its equivalent factor has adjusted to be 1.77.

(4) Pasture: the land used to foster domestic animals. It also provides ecological services such as water and soil conservation, absorption of pollution, etc. Its bio-productivity is lower than that of arable land. And the equivalent factor for pasture has adjusted to be 0.54 .

(5) Forest: the land to supply timber and wood products, wildlife products and many ecological services such as balancing of atmospheric $\mathrm{CO}_{2} / \mathrm{O}_{2}$, purifying pollutants, animal habitats and aesthetics value of landscapes. Its bio-productivity is generally lower than that of arable land, and the equivalent factor has adjusted to be 1.14 .

(6) Built-up areas: the land covered by human settlements such as buildings, houses and infrastructures (for example, traffic, wastes treatment plants and various kinds of pipe lines for tapwater, electricity, oil and gas, etc.). It always forms from arable land (Folke et al., 1997; Wackernagel et al., 1999a, 1999b; Rees, 2000), and its equivalent factor is the same as arable land (Wackernagel and Rees, 1996; Wackernagel et al., 1999a, 1999b; Rees, 2000) and has adjusted to 2.82 .

(7) Marine areas: it is a type of the earth surface for supplying humans with aquatic biomass, marine raw materials, marine energy and other ecological services such as marine biological habitat, climatic regulation, hydrological cycle, absorption of pollution and so on. Its equivalent factor has adjusted to 0.22 .

\subsubsection{Parameters for spatial transformation between global average bio-productive areas and solar space}

According to the common data of the sun radiation, the solar space coefficient (SSC) was calculated to be $1.9826 \mathrm{E}+10 \mathrm{Gj} / \mathrm{Sa}$-ha. The transformity of global bio-productive areas (TGB) is defined as a quantity of emergy ( $\mathrm{Gj} / \mathrm{Ga}$-ha) in a unit area of global average bioproductive areas (GABA) divided by SSC (Gj/Sa-ha), thus its value was calculated to be $6.7713 \mathrm{E}-04 \mathrm{Sa}-\mathrm{ha} / \mathrm{Ga}-\mathrm{ha}$. All of the above parameters are in a unit of time of a year (also see Appendix A).

\subsubsection{Equivalent and yield factors of the solar space on the earth} surface (ESS) (also see Appendix B)

(1) Equivalent factor of ESS (EFS) is defined to be the average intensity of solar radiation of ESS on the earth (IESS for short) (Gj/Ga-ha) divided by SSC (Gj/Sa-ha), and its value was calculated to be 2.7770E-06 Sa-ha/Ga-ha (it is denoted for EFS in short in this paper).

(2) Yield factor of ESS (EFGS) is the average intensity of solar radiation in a specific area on the earth surface $(\mathrm{Gj} / \mathrm{Ga}$-ha) divided by IESS (Gj/Ga-ha). For Yangzhou city, its value was calculated to be $8.5895 \mathrm{E}-01$.

\subsubsection{Emergy analysis}

Emergy analysis is an energy-based analytical method for assessing the dynamics of human-ecosystem interactions. Emergy is defined as the amount of energy required directly and indirectly to make a product or service. Emergy analysis needs to use a series of parameters of transformity. Transformity is the amount of one type of energy required to make a unit of energy of another type. A necessary parameter usually used in emergy analysis is solar transformity that is defined as "the amount of solar energy required directly and indirectly to make $1 \mathrm{~J}$ of a service or product" with a unit of sej/J, equaling the total amount of solar emergy of a product or service divided by its available energy (Odum, 1996). Since solar energy is a basis for calculating the emergy of any product or service, so the transformity of solar energy is defined as unity.

\subsubsection{Transformity for energy or products}

(1) The emergy of any energy or products may be calculated in the following formula:

$M=w \times D \times T_{r}$

where $M$ refers to the emergy amount of energy or products, $w$ is the amount of energy or products in a unit of weight or mass, $D$ is energy intensity, and $T_{r}$ is emergy transformity (Odum, 1996; Ulgiati et al., 1994), also see (3) in Appendix B.

(2) Solar space of fossil fuels or products (SYFP) may be calculated by the following:

$\mathrm{SYFP}=\frac{M_{0}}{\mathrm{SSC}}$

where $M_{0}$ is the emergy amount for a unit of specific energy or products, and SSC is the solar space coefficient. The SYFP values for some types of energy or products were listed in Table 1.

(3) Earth solar space of fossil fuels or products (GSYP) may be obtained as follows:

$\mathrm{GSYP}=\frac{\text { SYFP }}{\mathrm{EFS}}$

where SYFP is solar space equivalent of fossil fuels or other products (also see the formula (2)), EFS is the equivalent factor of ESS. The GSYP values for some types of energy or products were listed in Table 2.

\subsection{The calculation procedure of SS}

\subsubsection{The ecological supply and demand}

The calculation procedure of SS is similar to that of ecological footprint method (EF) (Wackernagel and Rees, 1996; Wackernagel et al., 1999a, 1999b), and ecosystems appropriation may be expressed in the following formula:

$\mathrm{PC}=\sum_{j=1}^{8} E_{j} \sum_{i=1}^{n}\left(C_{i} / P / \lambda_{i j}\right)$

where PC is ecosystems appropriation per capita, with a unit of Gaha or Sa-ha/capita; $C_{i}$ is total consumption of the $i$ th product or service; $P$ is total population; $\lambda_{i j}$ is global energy productivity or 
Table 1

The SYFP values for some types of fossil energy or products.

\begin{tabular}{ll}
\hline Categories of energy or products $(\mathrm{Gj})$ & SYFP value $(\mathrm{Sa}-\mathrm{ha} / \mathrm{Gj})$ \\
\hline Coal and other solid fossil fuels & $1.9369 \mathrm{E}-06$ \\
Liquid fossil fuel & $3.2080 \mathrm{E}-06$ \\
Natural gas or fossil gas fuel & $2.4211 \mathrm{E}-06$ \\
Bio-energy & $1.7603 \mathrm{E}-06$ \\
Nuclear energy & $1.0088 \mathrm{E}-05$ \\
Embodied energy of goods & $2.5220 \mathrm{E}-06$ \\
\hline
\end{tabular}

Table 2

The GSYP values for some types of fossil energy or products.

\begin{tabular}{ll}
\hline Categories of energy or products $(\mathrm{Gj})$ & GSYP value $(\mathrm{Ga}-\mathrm{ha} / \mathrm{Gj})$ \\
\hline Coal and other solid fossil fuels & $6.9747 \mathrm{E}-01$ \\
Liquid fossil fuel & $1.1552 \mathrm{E}+00$ \\
Natural gas or fossil gas fuel & $8.7184 \mathrm{E}-01$ \\
Bio-energy & $6.3390 \mathrm{E}-01$ \\
Nuclear energy & $3.6327 \mathrm{E}+00$ \\
Embodied energy in goods & $9.0817 \mathrm{E}-01$ \\
Average of the above & $1.3982 \mathrm{E}+00$ \\
\hline
\end{tabular}

bio-productivity of the $i$ th product or service for the $j$ th type of space whose unit of measure may be expressed in terms of global average bio-productive areas or solar space on the earth (ESS). $E_{j}$ is the equivalent factor of the $j$ th type of space, it represents the ratio of energy productivity or bio-productivity of the $j$ th type of space on the earth to energy productivity of solar space on the earth surface (ESS) or global average bio-productivity (also see Section 2.2.3). In our study, there are all together eight main items of spaces (see Sections 2.1 and 2.2). The ecological supply may be expressed in the following:

$\mathrm{PS}=\sum_{j=1}^{8} \frac{E_{j} \times Y_{j} \times S_{j}}{P}$

where PS is ecological supply per capita, with the same unit as the variable PC in the formula (4), $P$ is total population, and $S_{j}$ is total available area of the $j$ th type of space in that year; $Y_{j}$ is yield factor of the $j$ th type of space, it represents the ratio of available energy output or bio-yield of the $j$ th type of local space to its average energy output or bio-yield of the $j$ th type of space on the earth, and this calculation is similar to the yield factor of ESS (see Section 2.2.3); $E_{j}$ has the same meaning as that in the formula (4).

The equilibrium of ecological supply and demand is obtained as follows:

$\mathrm{PU}=\mathrm{PS}-\mathrm{PC}$

PU is ecological equilibrium per capita. It refers to: (1) ecological surplus when the result is positive ( $P U>0),(2)$ ecological deficit when it is negative $(\mathrm{PU}<0)$, and $(3)$ ecological equilibrium when the result is zero.

\subsubsection{Ecosystems appropriation (demand) per capita}

(1) Per capita ecosystems appropriation of global bio-productive areas for individual items of consumption: Dividing the total consumption of the $i$ th product or service from the $j$ th type of space in that year by the corresponding global average productivity of the $i$ th product or service on the $j$ th type of space, then dividing it by total population, and then multiplying it by the equivalent factor of the $j$ th type of space. This calculation is similar to that in EF analysis (Wackernagel et al., 1999a, 1999b) and the calculating parameters were already modified in SS analysis (also see Section 2.2.1).

$e f_{i}=\frac{P_{i}+I_{i}-E_{i} / Y_{i j}}{P_{0} \times Q_{i}}$

where $e f_{i}$ is per capita ecosystems appropriation of the $i$ th product or service; $P_{i}$ is annual output of the $i$ th product or service on the $j$ th type of space, and $I_{i}, E_{i}$ are respectively total amount of import and export of the $i$ th product or service; $Y_{i j}$ is the global average productivity (in a unit of biomass) of the $i$ th product or service on the $j$ th type of space. $P_{0}$ is total population, and $Q_{i}$ is the equivalent factor for the $j$ th type of space.

(2) Per capita ecosystems appropriation of the earth solar space (ESS): Dividing the total consumption of the ith product or service on the $j$ th type of space by total population in the calculating year, then multiplying the result with its energy intensity, and then multiplying it by the earth solar space equivalent of fossil fuels or products (GSYP), also see the formula (3). If it is necessary to transform it into a unit of solar space, then the result should be multiplied by the equivalent factor of ESS (EFS).

$S P_{i}=C_{i} \times D \times \mathrm{GSYP}_{i} \times \mathrm{EFS}$

where $C_{i}$ is per capita consumption of the $i$ th energy or products, $D$ refers to energy intensity, $\mathrm{GSYP}_{i}$ is earth solar space equivalent of the ith consumed energy or products, and EFS is equivalent factor of ESS.

(3) Per capita ecosystems appropriation of solar space: Dividing the total consumption of the $i$ th consumed product or service on the $j$ th of space by total population in a year, and multiplying it with its energy intensity, and then multiplying it with solar space equivalent of energy or products (SYFP).

(4) The summed per capita ecosystems appropriation of global average bio-productive areas can be calculated from the published references of EF (Wackernagel et al., 1999a, 1999b). If it is necessary to transform it to a unit of solar space, and it needs multiply the transformity of global bioproductive areas (TGB), see Section 2.2.2, that is derived from the formula (7):

$\mathrm{SC}=\left(\sum_{i=1}^{n} e f_{i}\right) \times \mathrm{TGB}, \quad i=1,2, \ldots n$

where SC is the summed per capita ecosystems appropriation equivalent of global average bio-productive areas, $e f_{i}$ is per capita ecosystems appropriation of the $i$ th product or service.

\subsubsection{Supply per capita}

(1) Per capita supply of global average bio-productive areas is the product of per capita local available area of land (ha/capita) for the $j$ th of space and its yield factor, whose calculating method is similar to that of EF (Wackernagel et al., 1999a, 1999b).

(2) Per capita supply of local solar space is calculated by dividing the total area of local land where solar energy radiation is available in the area by local population, and then multiplying the remaining coefficient of local solar radiation, also see (4) in Appendix B.

$\mathrm{PSL}=\frac{A}{P_{0}} \times f$

where $A$ is the area of available local land, $P_{0}$ is local population, $f$ is the remaining coefficient of local solar radiation.

Per capita supply in terms of earth solar space (ESS) is the product of per capita actual supply of local solar radiation and 
the yield factor of solar space (EFGS), also see Section 2.2 .3 for EFGS.

$\mathrm{PSE}=\mathrm{PSL} \times \mathrm{EFGS}$

where PSE is per capita supply equivalent in terms of ESS, and PSL is defined in the formula (10).

(3) The summed per capita supply of ESS is calculated by multiplying PSE in Eq. (11) with EFS, see (1) in Section 2.2.3, and then plus the product of per capita supply of global average bio-productive areas and the transformity of global bioproductive areas (TGB).

$\mathrm{TSP}=\mathrm{PSL} \times \mathrm{EFGS} \times \mathrm{EFS}+\mathrm{PSG} \times \mathrm{TGB}$

where TSP is the summed per capita supply in terms of ESS, PSG is per capita supply of global average bio-productive areas, also see (1) in this section.

\subsubsection{Ecological surplus and deficit}

(1) Absolute ecological surplus: it is the difference by subtracting the summed per capita equivalent of demand from the summed per capita equivalent of supply. Also see the formula (6) in Section 2.3.1.

(2) Relative ecological surplus: it is calculated by subtracting the summed equivalent of per capita ecosystems appropriation from the summed equivalent of per capita supply, and then dividing by the summed equivalent of per capita supply, and finally multiplying it by $100 \%$.

RES $=\frac{\text { PS }- \text { PC }}{\text { PS }} \times 100 \%$

where RES is the relative ecological surplus, and PS and PC are defined in the formula (6).

\section{A case study: ecosystems appropriation analysis of Yangzhou city, Jiangsu province of East China}

\subsection{The characteristics of Yangzhou city}

Yangzhou locates between east longitude $119^{\circ} 01^{\prime}$ to $119^{\circ} 54^{\prime}$, and north latitude $31^{\circ} 56^{\prime}$ to $33^{\circ} 25^{\prime}$ (see Fig. 1), and is a famous long-historic city in Jiangsu province, East China. It belongs to the subtropical humid zone and there clearly exists four seasons in a year. It is mild with an annual average temperature $15^{\circ} \mathrm{C}$ and its annual mean precipitation is $1030 \mathrm{~mm}$.
The total area of the city is $6638 \mathrm{~km}^{2}$ and Yangtze River flows through its south area. Additionally, there are lots of small rivers (46 rivers) and lakes ( 3 big lakes) within its territory, so the city is very abundant in water resource. But water pollution is relatively serious and the natural disasters are mainly flood, drought, and water logging (Yangzhou Environmental Protection Bureau, 2001).

The solar energy resource of its territory is abundant with an annual radiation of $113 \mathrm{kcal} / \mathrm{cm}^{2}$, which is higher than that in the southern areas of Jiangsu province. Although the arable land of the city is only 1.05 Chinese mu ( $1 \mathrm{ha}=15 \mathrm{mu}$ ) per capita, the land productivity is high.

In the year 2000, the population was 4.506 million (3.28 million living in the rural area, and 1.12 million in the urban areas). The GDP is 47.21 billion RMB yuan (Chinese currency, $1 \$=8.0 \mathrm{RMB}$ yuan in 2000), per capita GDP was about 11 thousand RMB yuan, and per capita income and expenditure were respectively 5099 RMB yuan and 3651 RMB yuan (Yangzhou Statistic Bureau, 2001).

Our following analysis includes three parts: (1) estimating the actual demand for ecological space of the city's production, consumption and uses of ecological services; (2) estimating the local ecological supply; and (3) analyzing the status of equilibrium for demand and supply.

The data of production, consumption and wastes discharge came from local Statistical Yearbook (Yangzhou Environmental Protection Bureau, 2001) and Environmental Monitoring Annual Reports 2000 (Yangzhou Environmental Protection Bureau, 2001); the data about land use was obtained from the data of Yangzhou Land Use Plan Report (The People's Government of Yangzhou City, 1998).

\subsection{The ecological demand of Yangzhou city}

The ecological demand of Yangzhou in the year 2000 was listed in Tables 3 and 4 . The table contained the demands of 8 types of ecological space and 11 kinds of products and ecological services. The ranking of ecosystems appropriation per capita appeared in a descending order: arable land $>$ solar space $>$ built-up area$\mathrm{s}>$ freshwater areas $>$ pasture $>$ garden land $>$ forest $>$ marine areas. The summed per capita ecosystems appropriation equivalent of earth surface space was $6.6975 \mathrm{E}-01 \mathrm{Ga}-\mathrm{ha}$, and its equivalent of solar space was $5.8761 \mathrm{E}-04 \mathrm{Sa}-\mathrm{ha}$.

\subsection{The ecological supply of Yangzhou city}

The ecological supply in the year 2000 was listed in Table 5. It involved eight types of ecological space. The per capita equivalent of

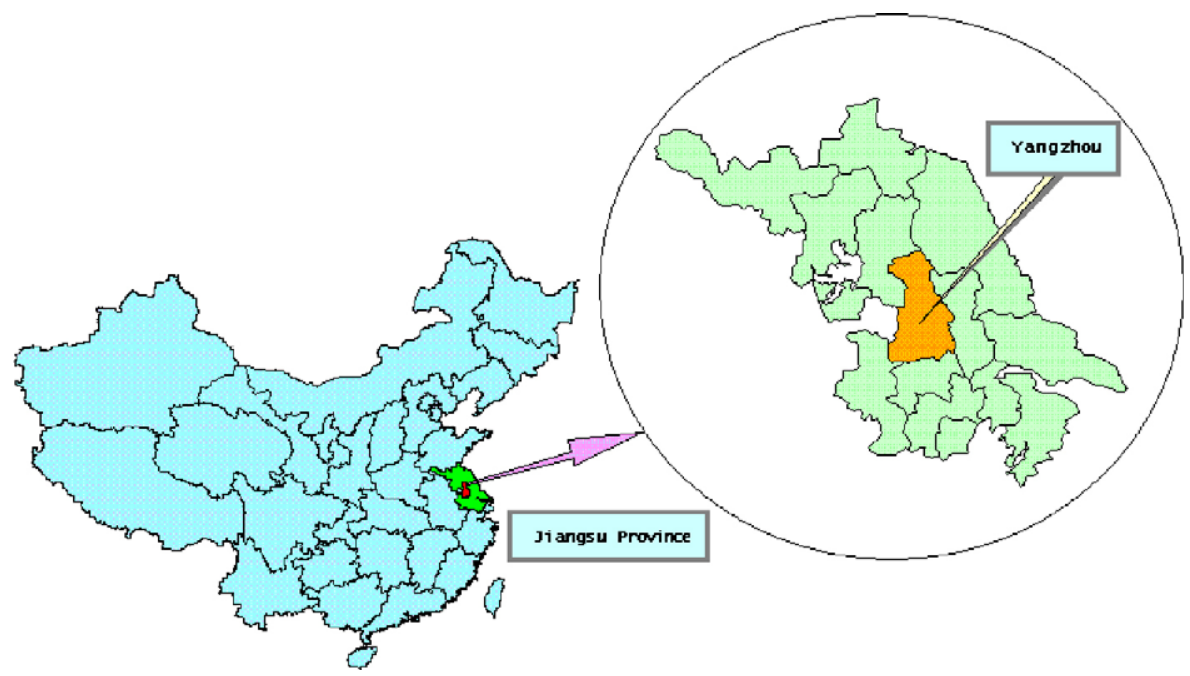

Fig. 1. The geographic location of Yangzhou city, Eastern China. 
Table 3

The demands of ecological space by category in Yangzhou city in the year 2000.

\begin{tabular}{|c|c|c|c|c|c|c|c|}
\hline Categories & $\begin{array}{l}\text { Output of raw } \\
\text { materials (ton) }\end{array}$ & $\begin{array}{l}\text { Actual } \\
\text { consumption } \\
\text { (ton) }\end{array}$ & $\begin{array}{l}\text { Productivity of } \\
\text { earth solar space } \\
\text { (GSYP) (Ga-ha/fossil } \\
\text { energy Gj) }\end{array}$ & $\begin{array}{l}\text { Productivity of } \\
\text { average } \\
\text { bio-productive } \\
\text { areas (kg/Ga-ha) }\end{array}$ & $\begin{array}{l}\text { Yield of local } \\
\text { bio-productive } \\
\text { areas (kg/ha) }\end{array}$ & $\begin{array}{l}\text { Per capita } \\
\text { ecological } \\
\text { appropriation } \\
\text { (ha/capita) }\end{array}$ & Space categories \\
\hline \multicolumn{8}{|l|}{ 1. Plant based food } \\
\hline 1.1 Grains & $2.2516 \mathrm{E}+06$ & $1.0901 \mathrm{E}+06$ & - & $4.5164 \mathrm{E}+03$ & $6.2830 \mathrm{E}+03$ & $5.3563 \mathrm{E}-02$ & Arable land \\
\hline 1.2 Vegetables and melons & $1.1940 \mathrm{E}+06$ & $5.2569 \mathrm{E}+05$ & - & $1.8000 \mathrm{E}+04$ & $2.3006 \mathrm{E}+04$ & $6.4811 \mathrm{E}-03$ & Arable land \\
\hline 1.3 Fruits & $2.6861 \mathrm{E}+04$ & $1.1293 \mathrm{E}+05$ & - & $1.2000 \mathrm{E}+04$ & $1.5141 \mathrm{E}+04$ & $2.0884 \mathrm{E}-03$ & Garden land \\
\hline 1.4 Sugar & $1.4581 \mathrm{E}+04$ & $7.8389 E+03$ & - & $5.0595 \mathrm{E}+03$ & $1.2151 \mathrm{E}+04$ & $3.4382 \mathrm{E}-04$ & Arable land \\
\hline 1.5 Oil plants & $1.2463 \mathrm{E}+05$ & $5.1738 \mathrm{E}+04$ & - & $8.3093 \mathrm{E}+02$ & $2.0910 \mathrm{E}+03$ & $1.3817 \mathrm{E}-02$ & Arable land \\
\hline $\begin{array}{l}\text { 1.6 Tea or other plant based } \\
\text { food or drinks }\end{array}$ & $4.0300 \mathrm{E}+02$ & $4.6631 \mathrm{E}+03$ & - & $1.1820 \mathrm{E}+03$ & $3.5950 \mathrm{E}+02$ & $1.2914 \mathrm{E}-03$ & Garden land \\
\hline \multicolumn{8}{|l|}{ 2. Animal based food products } \\
\hline 2.1 Pork & $1.3412 \mathrm{E}+05$ & $6.7288 \mathrm{E}+04$ & - & $3.7592 \mathrm{E}+02$ & $6.1846 \mathrm{E}+02$ & $3.9722 \mathrm{E}-02$ & Arable land \\
\hline 2.2 Beef and mutton & $7.4120 \mathrm{E}+03$ & $1.2265 \mathrm{E}+03$ & - & $3.1986 \mathrm{E}+01$ & $7.6729 E+02$ & $8.5092 \mathrm{E}-03$ & Pasture \\
\hline 2.3 Poultry & $1.0348 \mathrm{E}+05$ & $3.6707 \mathrm{E}+04$ & - & $3.7592 \mathrm{E}+02$ & $6.0624 \mathrm{E}+02$ & $2.1669 \mathrm{E}-02$ & Arable land \\
\hline 2.4 Milk & $3.2340 \mathrm{E}+03$ & $2.8090 \mathrm{E}+04$ & - & $4.8926 \mathrm{E}+02$ & $8.6087 \mathrm{E}+02$ & $1.2741 \mathrm{E}-02$ & Arable land \\
\hline 2.5 Eggs & $1.4429 \mathrm{E}+05$ & $3.4248 \mathrm{E}+04$ & - & $5.3380 \mathrm{E}+02$ & $7.1739 E+02$ & $1.4238 \mathrm{E}-02$ & Arable land \\
\hline 2.6 Freshwater products & $2.2669 \mathrm{E}+05$ & $4.2502 \mathrm{E}+04$ & & $2.1364 \mathrm{E}+02$ & $4.3594 \mathrm{E}+03$ & 4.4149E-02 & Freshwater areas \\
\hline 2.7 Marine products & $0.0000 \mathrm{E}+00$ & $6.7593 E+03$ & - & $3.3423 \mathrm{E}+01$ & $0.0000 \mathrm{E}+00$ & 4.4879E-02 & Marine areas \\
\hline \multicolumn{8}{|l|}{ 3. Non fiber, non-food products } \\
\hline Tobacco & - & $1.6100 \mathrm{E}+04$ & - & $1.5000 \mathrm{E}+03$ & - & $2.3901 \mathrm{E}-03$ & Garden land \\
\hline 4. Timber products & $2.1700 \mathrm{E}+03$ & $2.9839 E+04$ & - & $1.3930 \mathrm{E}+03$ & $2.7206 \mathrm{E}+02$ & $9.2032 \mathrm{E}-03$ & Forest land \\
\hline \multicolumn{8}{|l|}{ 5. Non-timber plant fibers } \\
\hline $\begin{array}{l}\text { 5.1 Cotton and } \\
\text { cotton-related fibers }\end{array}$ & $8.6450 \mathrm{E}+03$ & $6.0116 \mathrm{E}+03$ & - & $1.0000 \mathrm{E}+03$ & $9.5300 \mathrm{E}+02$ & $1.3341 \mathrm{E}-03$ & Arable land \\
\hline 5.2 Woolen fabric & $8.0286 E+03$ & $6.6848 \mathrm{E}+02$ & - & $1.5993 \mathrm{E}+01$ & $3.8364 \mathrm{E}+02$ & $9.2755 \mathrm{E}-03$ & Pasture \\
\hline 5.3 Linen & $1.0500 \mathrm{E}+02$ & $5.2500 \mathrm{E}+01$ & - & $1.6380 \mathrm{E}+03$ & $5.2500 \mathrm{E}+02$ & $7.1127 \mathrm{E}-06$ & Arable land \\
\hline 5.4 Silks & $1.9626 \mathrm{E}+03$ & $9.8130 \mathrm{E}+02$ & - & $7.2082 \mathrm{E}+01$ & $8.9353 \mathrm{E}-01$ & $3.0211 \mathrm{E}-03$ & Garden land \\
\hline 5.5 Chemical fibers & $5.4040 \mathrm{E}+05$ & $2.1616 E+04$ & $9.0817 \mathrm{E}-01$ & - & - & $2.1782 \mathrm{E}-01$ & $\mathrm{ESS}^{\mathrm{a}}$ \\
\hline 5.6 Leather products & $1.1610 \mathrm{E}+05$ & $8.5855 \mathrm{E}+03$ & - & $3.1986 \mathrm{E}+01$ & $7.6729 \mathrm{E}+02$ & $5.9564 \mathrm{E}-02$ & Pasture \\
\hline 6. Chemical products & $3.6766 \mathrm{E}+05$ & $1.1487 \mathrm{E}+06$ & $9.0817 \mathrm{E}-01$ & - & - & $9.8318 \mathrm{E}+00$ & $\mathrm{ESS}^{\mathrm{a}}$ \\
\hline $\begin{array}{l}\text { 7. Non-metallic mineral } \\
\text { and products }\end{array}$ & $9.1000 \mathrm{E}+05$ & $4.5500 \mathrm{E}+05$ & $9.0817 \mathrm{E}-01$ & - & - & $4.5849 \mathrm{E}-01$ & $\mathrm{ESS}^{\mathrm{a}}$ \\
\hline $\begin{array}{l}\text { 8. Metallic mineral and } \\
\text { products }\end{array}$ & $5.0848 E+06$ & $1.2851 \mathrm{E}+06$ & $9.0817 \mathrm{E}-01$ & - & - & $1.0121 \mathrm{E}+01$ & $\mathrm{ESS}^{\mathrm{a}}$ \\
\hline 9. Energy (Gj) & $4.2897 \mathrm{E}+10$ & $1.6656 \mathrm{E}+17$ & $1.3982 \mathrm{E}+00$ & - & - & $2.76 \mathrm{E}+01$ & $\mathrm{ESS}^{\mathrm{a}}$ \\
\hline 10. Freshwater supply & $2.2400 \mathrm{E}+09$ & $3.2510 \mathrm{E}+09$ & - & $3.0338 \mathrm{E}+01$ & $8.7189 \mathrm{E}+02$ & $6.0912 \mathrm{E}-03$ & Freshwater areas \\
\hline 11. Absorption of pollution & - & $1.5869 \mathrm{E}+08$ & - & $7.6163 E+01$ & $8.7189 \mathrm{E}+02$ & $1.0930 \mathrm{E}-01$ & Freshwater areas \\
\hline
\end{tabular}

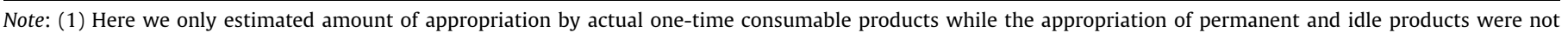

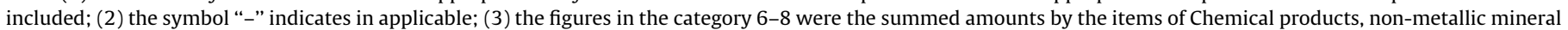

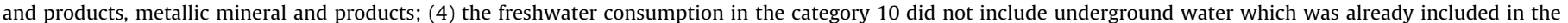

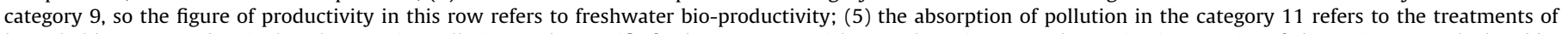

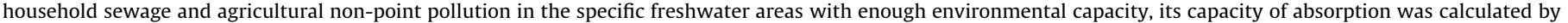
some data of biological absorption-transformation ratios, and the figures in the third column of category 11 refers to the total amount of pollution treated.

a ESS is the abbreviation of the phrase "earth solar space".

ecological supply appeared in a descending order: freshwater areas $>$ arable land $>$ built-up areas $>$ garden land $>$ forest $>$ solar space $>$ pasture $>$ marine areas. The summed per capita equivalent of ecological supply of earth surface space was 6.4669E-01 Ga-ha, and its equivalent of solar space was $4.3817 \mathrm{E}-04$ Sa-ha.

\subsection{The equilibrium of ecological supply and demand in Yangzhou city}

The ecological supply and demand in the year 2000 was listed in Table 6 . The absolute ecological surplus was found in freshwater areas and built-up areas; and the ecological deficit appeared in a descending order: solar space $>$ arable land $>$ pasture $>$ forest $>$ marine areas $>$ garden land. The summed per capita supply equivalent of earth surface space was less than that of demand, and the deficit was per capita 2.3063E-02 Ga-ha. In terms of solar space, the deficit was per capita 1.4944E-04 Ga-ha. Moreover, the ecological surplus appeared in freshwater areas and built-up areas and they respectively had a surplus of $82.66 \%$ and $8.62 \%$. The ecological deficit was as follows in a descending order: solar space $>$ pasture $>$ forest $>$ arable land $>$ garden land.

\section{Discussions}

\subsection{The methodological comparisons of SS and EF}

SS and EF are the two useful methodological tools for analyzing human appropriation of ecosystems, they are both spatial-based approaches for analyzing human impacts on ecosystems, but there are some individual characteristics (or differences) between them. We make a comparison in the following.

\section{(1) Measures of energy or mass equivalence}

Solar space method (SS) is based on a spatial measure of energy productivity as the concept of solar space, so this measure includes the various processes of mass and energy in its analysis. In SS, there are several alternative energy-based measures to represent ecosystems appropriation. Usually, we use two scales of solar space and earth solar space (ESS), they may convert each other through their equivalents of energy productivity. In contrast, EF is based on a spatial measure of bio-productivity areas on the earth and fossil energy land, which is only valid for the analysis of appropriation in relation 
Table 4

The ecological demand of Yangzhou city in the year 2000.

\begin{tabular}{|c|c|c|c|c|}
\hline Categories of space & Local demand by category (Ga-ha/capita) & Equivalent factor & Global space (Ga-ha/capita) & Solar space (Sa-ha/capita) \\
\hline Arable land & $1.5531 \mathrm{E}-01$ & $2.8219 \mathrm{E}+00$ & $4.3826 \mathrm{E}-01$ & $2.9676 \mathrm{E}-04$ \\
\hline Garden land & $8.7911 \mathrm{E}-03$ & $1.7745 \mathrm{E}+00$ & $1.5600 \mathrm{E}-02$ & $1.0563 \mathrm{E}-05$ \\
\hline Pasture & $9.0090 \mathrm{E}-02$ & $5.4110 \mathrm{E}-01$ & $4.8747 \mathrm{E}-02$ & $3.3008 \mathrm{E}-05$ \\
\hline Forest & $1.2898 \mathrm{E}-02$ & $1.1387 \mathrm{E}+00$ & $1.4686 \mathrm{E}-02$ & $9.9445 \mathrm{E}-06$ \\
\hline Solar space (indirect + direct) & $4.8290 \mathrm{E}+01$ & $2.7770 \mathrm{E}-06$ & - & $1.3410 \mathrm{E}-04$ \\
\hline Built-up areas & $2.6480 \mathrm{E}-02$ & $2.8219 \mathrm{E}+00$ & $7.4722 \mathrm{E}-02$ & $5.0596 \mathrm{E}-05$ \\
\hline Freshwater areas & $1.5954 \mathrm{E}-01$ & $4.2610 \mathrm{E}-01$ & $6.7979 \mathrm{E}-02$ & $4.6031 \mathrm{E}-05$ \\
\hline Marine areas & $4.4935 \mathrm{E}-02$ & $2.1719 \mathrm{E}-01$ & $9.7595 \mathrm{E}-03$ & $6.6084 \mathrm{E}-06$ \\
\hline Total global space & $4.9804 \mathrm{E}-01$ & - & $6.6975 \mathrm{E}-01$ & $4.5351 \mathrm{E}-04$ \\
\hline Total solar space & - & - & - & $5.8761 \mathrm{E}-04^{\mathrm{a}}$ \\
\hline
\end{tabular}

a The figures of total solar space in the table included the amount of total global space.

Table 5

The ecological supply of Yangzhou city in the year 2000 .

\begin{tabular}{|c|c|c|c|c|}
\hline Categories of space & Local supply by category (Ga-ha/capita) & Yield factor & Global space (Ga-ha/capita) & Solar space (Sa-ha/capita) \\
\hline Arable land & $7.1871 \mathrm{E}-02$ & $1.2187 \mathrm{E}+00$ & $2.4717 \mathrm{E}-01$ & $1.6736 \mathrm{E}-04$ \\
\hline Garden land & $3.0263 \mathrm{E}-03$ & $2.3482 \mathrm{E}+00$ & $1.2610 \mathrm{E}-02$ & $8.5387 \mathrm{E}-06$ \\
\hline Pasture & $1.0718 \mathrm{E}-04$ & $2.8555 \mathrm{E}+00$ & $1.6561 \mathrm{E}-04$ & $1.1214 \mathrm{E}-07$ \\
\hline Forest & $1.7700 \mathrm{E}-03$ & $5.9321 \mathrm{E}-01$ & $1.1956 \mathrm{E}-03$ & $8.0960 \mathrm{E}-07$ \\
\hline Solar space (direct) & $1.3298 \mathrm{E}-01$ & $8.5895 \mathrm{E}-01$ & $1.1422 \mathrm{E}-01$ & $3.1720 \mathrm{E}-07$ \\
\hline Built-up areas & $2.3777 \mathrm{E}-02$ & $1.2187 \mathrm{E}+00$ & $8.1770 \mathrm{E}-02$ & $5.5369 \mathrm{E}-05$ \\
\hline Freshwater areas & $4.5080 \mathrm{E}-02$ & $2.0406 \mathrm{E}+01$ & $3.9197 \mathrm{E}-01$ & $2.6541 \mathrm{E}-04$ \\
\hline Marine areas & $0.0000 \mathrm{E}+00$ & $1.0000 \mathrm{E}+00$ & $0.0000 \mathrm{E}+00$ & $0.0000 \mathrm{E}+00$ \\
\hline Total global space & $1.4776 \mathrm{E}-01$ & - & $6.4669 \mathrm{E}-01^{\mathrm{a}}$ & $4.3789 \mathrm{E}-04^{\mathrm{a}}$ \\
\hline Total solar space & - & - & - & $4.3817 \mathrm{E}-04^{\mathrm{a}, \mathrm{b}}$ \\
\hline
\end{tabular}

a About $12 \%$ of the global or solar space is assumed to be conserved for maintaining ecosystems services.

b The supply of solar space per capita in the table included global space.

Table 6

The equilibrium status of ecological space in Yangzhou city in the year 2000.

\begin{tabular}{|c|c|c|c|c|}
\hline Categories of spaces & $\begin{array}{l}\text { Absolute ecological surplus } \\
\text { (Ga-ha/capita) }\end{array}$ & $\begin{array}{l}\text { Relative ecological } \\
\text { surplus (\%) }\end{array}$ & $\begin{array}{l}\text { Co-opted equivalent of global } \\
\text { space (Ga-ha/capita) }\end{array}$ & $\begin{array}{l}\text { Supplied equivalent of solar } \\
\text { space (Sa-ha/capita) }\end{array}$ \\
\hline Arable land & $-1.9109 \mathrm{E}-01$ & -77.31 & $4.3826 \mathrm{E}-01$ & $2.4717 \mathrm{E}-01$ \\
\hline Garden land & $-2.9896 \mathrm{E}-03$ & -23.71 & $1.5600 \mathrm{E}-02$ & $1.2610 \mathrm{E}-02$ \\
\hline Pasture & $-4.8582 \mathrm{E}-02$ & -29334.42 & $4.8747 \mathrm{E}-02$ & $1.6561 \mathrm{E}-04$ \\
\hline Forest & $-1.3491 \mathrm{E}-02$ & -1128.32 & $1.4686 \mathrm{E}-02$ & $1.1956 \mathrm{E}-03$ \\
\hline Solar space & $-1.3378 \mathrm{E}-04$ & -42177.17 & $1.3410 \mathrm{E}-04$ & $3.1720 \mathrm{E}-07$ \\
\hline Built-up areas & $7.0479 \mathrm{E}-03$ & 8.62 & $7.4722 \mathrm{E}-02$ & $8.1770 \mathrm{E}-02$ \\
\hline Freshwater areas & 3.2399E-01 & 82.66 & $6.7979 E-02$ & $3.9197 \mathrm{E}-01$ \\
\hline Marine areas & $-9.7595 \mathrm{E}-03$ & - & $9.7595 \mathrm{E}-03$ & $0.0000 \mathrm{E}+00$ \\
\hline Total global space & $-2.3063 \mathrm{E}-02$ & -3.68 & $6.6975 \mathrm{E}-01$ & $6.4669 \mathrm{E}-01$ \\
\hline Total solar space & $-1.4944 \mathrm{E}-04$ & -154.86 & $5.8761 \mathrm{E}-04$ & $4.3817 \mathrm{E}-04^{\mathrm{a}}$ \\
\hline
\end{tabular}

Note: “-" indicates ecological deficit while"+" denotes surplus.

${ }^{a}$ The total solar space per capita in the table included global space.

to bio-productivity. In addition, the concept of fossil energy land is only valid for carbon-dependent processes of energy appropriation, and excludes other categories of energy appropriation.

(2) Applicability to different analyses of appropriation

Energy processes of the earth surface have more essential and extensive roles than biological or ecological processes, and solar energy is one of the main driving forces to sustain the earth system (including any eco-systems on the earth). The proposed concept of solar space has much clearer bio-physical implications in measuring ecosystems appropriation than the "fossil energy land" in EF, which increases the applicability of $\mathrm{SS}$ in contrast to EF approach.

EF only takes into account of arable land, pasture, forest land, built-up areas, fishing ponds and marine areas while SS easily includes freshwater areas (aquaculture and water supply) as an independent type of space in its analysis, and separates garden land from arable land to become another type of ecological space. Garden land is an intensively managed land with a coverage of over $50 \%$, that usually grows perennial woody or herbage crops (including their nursery garden), fruits, leaf, root or stem (e.g. plantations for fruit, mulberry, tea, rubber, coffee, flowers, medicinal herbs and so on). So the land classification system in SS consists of eight items which are arable land, garden land, pasture, forest, freshwater areas, built-up areas, marine areas and solar space. This modified classification system may reduce an underestimate of ecosystems appropriation caused by neglecting some types of ecological space in EF.

SS is a synthetic process-based approach of ecosystems appropriation and has some advantages to calculate the appropriation of process-based ecological services. It may not only calculate the appropriation of forest used as carbon sink of $\mathrm{CO}_{2}$, but also be more feasible to involve other appropriations of ecological services which are hard to count by EF, such as regulating atmospheric balance, biogeochemical cycle, hydrological balance, and pollution absorption, water conservation, uses of biomass energy and non-carbon natural 
energy (such as wind energy, terrestrial heat, nuclear energy and solar energy). In the calculating process of ecosystems appropriation, it is very necessary to avoid double counting because the two facts usually co-exist that the same type of ecosystems possesses multi-services and that different ecosystems possibly have certain similar ecological services. In our calculation, two categories of ecosystems appropriation that were not usually counted in EF were reasonably included: (i) pollution absorption for household sewage, farmland pesticide and chemical fertilizer, and (ii) supply of underground and surface waters.

(3) Direct and indirect appropriation of ecosystems

In SS, the energy intensity used in EF is replaced by emergy transformity that makes the analysis of appropriation be capable of including both direct and indirect consumption of energy or products. As shown in Sections 2 and 3, firstly we calculate the direct and indirect consumptions for each types of products and ecological services and transform them into emergy by multiplying emergy transformity (Odum, 1996; Ulgiati et al., 1994); then transform emergy amount of various types of consumptions into equivalent amounts of solar space in terms of energy productivity. Finally we aggregate all kinds of amounts of ecosystems appropriation in terms of ESS or solar space according to the proposed calculating formulas. If we want to calculate direct ecosystems appropriation of bioproducts relating to land bio-productivity, just follow the same calculating process as EF (see calculating formulae in Section 2.3). Obviously, SS includes the categories of indirect consumption that is not included in EF.

(4) Appropriation of non-bio-productive areas

EF is based on bio-productive characteristics of land on the earth, and does not involve appropriation of non bioproductive areas. For example, it is difficult to calculate the appropriation of non-carbon energy and ecosystems' absorption to non-carbon greenhouse gases because there exists an unclear or confused ecological context for using the concept of "fossil energy land" in EF analysis. But SS is based on an analysis of energy ecological processes, so appropriations of bioproductive and non bio-productive areas may both be counted according to analysis of energy fluxes. For example, the supply of ground freshwater or underground freshwater is an important type of appropriation and difficult to be included in $\mathrm{EF}$, but it may be calculated easily in SS.

In addition, SS is required to do calculations through ecosystem processes and thus may adjust the boundary of analysis in accordance with actual ecosystem characteristics, not being subject to any administrative boundaries, and make calculations more feasible and explicit in the ecosystems' context. This modification could better reflect spatial trades of ecosystems appropriation among regions by considering the difference in spatial patterns of ecosystems defined by their boundaries in the analysis of ecosystems appropriation.

(5) Dynamic complexity of ecosystems appropriation

SS is based on direct and indirect processes of ecosystems and their spatial patterns by integrating the advantages of the two methods of emergy analysis and ecological footprint. Therefore, it may accurately analyze the mass or energy processes and spatial patterns of ecosystems appropriation and further considers long-term or short-term dynamics as well as dynamics of spatial patterns of ecosystems appropriation while EF over-simplifies or excludes the processes of ecosystems appropriation, leading to a neglect of its complex dynamic behaviors. For example, SS needs to make clear the actual dynamics of sources, fluxes and sinks of mass or energy networks in ecosystems appropriation, and makes the static time-point analysis of ecosystems appropriation in EF become a dynamic process-based analysis. In the analysis of ecosystems appropriation by SS, there are several basic issues of dynamic complexity needing to be especially concerned: (i) hierarchies in temporal-spatial scales: hierarchical behaviors of ecosystems appropriation at different temporal and spatial scales, for example, how does the appropriation of a city relates to that of its urban areas, peri-urban areas and rural areas since they are at different spatial scales, etc.; (ii) uncertainty: there are much uncertainty appeared in the behaviors of ecosystems appropriation such as informative uncertainty due to the nonavailability or low quality of data; (iii) predictability: the appropriation of ecosystems is a kind of non-linear dynamic behaviors, and the predictability of its dynamic behaviors is subject to its temporal and spatial characteristics; (iv) linkages between temporal and spatial dynamic behaviors: the temporal and spatial behaviors of ecosystems appropriation are interrelated with each other, understanding the mechanisms for these linkages is necessary for improving the analysis of ecosystems appropriation.

Although the analysis of dynamics of ecosystems appropriation has not been done in the current research due to some existing difficulties such as data availability, the presentation of SS is a step of effort to help understand the complexity of ecosystems appropriation in the future study.

SS was developed to better describe the dynamics of ecosystems appropriation, and the key point for its methodology is to make it more applicable to analyze well the temporalspatial behaviors of ecosystems appropriation. At this point, the methodological comparison of SS, EF and emergy approach (EM) was summarized in Table 7.

\subsection{A quantitative comparison of the results between SS and EF}

There are obvious differences between SS and EF discussed in Section 3.1, and they are only comparable with each other in a certain extent. Here a quantitative comparison was conducted to observe how different the results between SS and EF analysis were. It is well realized that "fossil energy land" usually does not involve indirect consumption of energy or products. In contrast, "solar space" involves both direct and indirect consumptions. In terms of earth surface space, the calculations of ecosystems appropriation were made using SS and EF and the results were shown in Table 8. In the two scenarios of freshwater included and not included, the total per capita ecosystems appropriation is much bigger in SS than that in EF while the total equivalent amount for per capita ecological supply is approximately the same in both methods. The absolute and relative ecological deficits were much bigger in the former than that in the latter, no matter or not considering the freshwater component of appropriation, also see (5) in Appendix B.

As to the carbon absorption of ecosystems, the "fossil energy land" in EF analysis balances the carbon emission of human activities through the carbon fixation by forest ecosystems while the "solar space" in SS analysis may complete it in different ways, and usually take also the ecological processes of plant photosynthesis to fix the carbon element. The SS has various types of ecological spaces available to balance carbon discharge (the EF only takes forest) and its capacity of absorption is relatively much higher, and it could avoid some weaknesses caused by the former's assumption that forest is the only space for absorbing carbons from greenhouse gases. According to our preliminary estimation, the annual net capacity of indirect carbon absorption for solar space could reach as high as $1.66 \mathrm{Gg} / \mathrm{Sa}$-ha while that for "fossil energy land" is only $0.0017 \mathrm{Gg} / \mathrm{Ga}$-ha. 
Table 7

Methodological differences and similarities of SS, EF and emergy analysis (EM) in terms of ecosystems appropriation.

\begin{tabular}{|c|c|c|c|}
\hline & SS & $\mathrm{EF}$ & EM \\
\hline Connotation & $\begin{array}{l}\text { Embodied equivalent amount of } \\
\text { the solar surface directly and } \\
\text { indirectly required to make a } \\
\text { product or service }\end{array}$ & $\begin{array}{l}\text { Embodied equivalent amount } \\
\text { of the global bio-productive } \\
\text { surface required to make a } \\
\text { product or service }\end{array}$ & $\begin{array}{l}\text { The amount of energy required directly } \\
\text { and indirectly to make a product or } \\
\text { service, usually expressed as the amount } \\
\text { of solar energy }\end{array}$ \\
\hline Metric unit & Solar hectares (Sa-ha) & Global hectares (Ga-ha) & sej \\
\hline Measure of equivalence & $\begin{array}{l}\text { Average energy-productive areas } \\
\text { on the solar surface }\end{array}$ & $\begin{array}{l}\text { Global average bio-productive } \\
\text { areas on the earth }\end{array}$ & Solar emergy joules \\
\hline Temporal-spatial dependence & $\begin{array}{l}\text { Temporal (process) and spatial } \\
\text { dependent (based on boundaries } \\
\text { of ecosystems) }\end{array}$ & $\begin{array}{l}\text { Spatial dependent (based on } \\
\text { administrative or artificial } \\
\text { boundaries of ecosystems) } \\
\text { without relating to ecological } \\
\text { processes }\end{array}$ & $\begin{array}{l}\text { Temporal or process dependent (based on } \\
\text { boundaries of ecosystems) }\end{array}$ \\
\hline $\begin{array}{l}\text { Transformations among various } \\
\text { energy or mass }\end{array}$ & $\begin{array}{l}\text { Measured or calculated with } \\
\text { great accuracy }\end{array}$ & $\begin{array}{l}\text { Measured or calculated with low } \\
\text { or very low accuracy (based on } \\
\text { some assumptions) }\end{array}$ & Measured or calculated with great accuracy \\
\hline $\begin{array}{l}\text { Dependence of measure on } \\
\text { energy or mass }\end{array}$ & $\begin{array}{l}\text { Energy-dependent (usually } \\
\text { solar-based) }\end{array}$ & $\begin{array}{l}\text { Carbon-dependent (exclusively } \\
\text { based on the carbon absorption } \\
\text { of bio-productive areas) }\end{array}$ & Energy-dependent (usually solar-based) \\
\hline Associations with human economy & High & Moderate & High \\
\hline Associations with ecological complexity ${ }^{a}$ & Applicable for dynamic analysis & $\begin{array}{l}\text { Not applicable for dynamic } \\
\text { analysis (very simplified static } \\
\text { behavioral description of ecosystems }\end{array}$ & Applicable for dynamic analysis \\
\hline $\begin{array}{l}\text { Applicability to analysis } \\
\text { of appropriation }\end{array}$ & $\begin{array}{l}\text { Broad (direct and indirect), and } \\
\text { applicable to all the energy or } \\
\text { mass-related categories of } \\
\text { appropriation (including non } \\
\text { bio-productive areas) }\end{array}$ & $\begin{array}{l}\text { Narrow (direct), and applicable to } \\
\text { limited categories of appropriation } \\
\text { (only including bio-productive areas) }\end{array}$ & $\begin{array}{l}\text { Broad (direct and indirect), and applicable } \\
\text { to all the energy or mass-related categories } \\
\text { of appropriation (including non } \\
\text { bio-productive areas) }\end{array}$ \\
\hline
\end{tabular}

${ }^{a}$ Ecological complexity denotes those behaviors such as predictability, multi-scale hierarchy, non-linearity, uncertainty, etc.

Table 8

The comparison of the differences between the results of SS and EF (unit: Ga-ha/capita, \%).

\begin{tabular}{|c|c|c|c|c|}
\hline Categories of space & $\begin{array}{l}\text { Demand } \\
\text { (Ga-ha/capita) }\end{array}$ & $\begin{array}{l}\text { Supply } \\
\text { (Ga-ha/capita) }\end{array}$ & $\begin{array}{l}\text { Absolute ecological } \\
\text { surplus (Ga-ha/capita) }\end{array}$ & $\begin{array}{l}\text { Relative ecological } \\
\text { surplus (\%) }\end{array}$ \\
\hline \multicolumn{5}{|l|}{ SS } \\
\hline $\begin{array}{l}\text { Including freshwater and indirect } \\
\text { energy consumption }\end{array}$ & $2.5705 \mathrm{E}+00$ & $6.4669 \mathrm{E}-01$ & $-1.9239 \mathrm{E}+00$ & 261.79 \\
\hline $\begin{array}{l}\text { Not including freshwater and indrect } \\
\text { energy consumption }\end{array}$ & $2.5026 \mathrm{E}+00$ & $3.0176 \mathrm{E}-01$ & $-2.2008 \mathrm{E}+00$ & 641.81 \\
\hline \multicolumn{5}{|l|}{$\mathrm{EF}$} \\
\hline Including freshwater & $1.4324 \mathrm{E}+00$ & $6.4669 \mathrm{E}-01$ & $-7.8573 \mathrm{E}-01$ & 106.92 \\
\hline Not including freshwater & $1.3644 \mathrm{E}+00$ & $3.0176 \mathrm{E}-01$ & $-1.0627 \mathrm{E}+00$ & 309.90 \\
\hline
\end{tabular}

Note: “-” indicates ecological deficit while "+" indicates ecological surplus.

\section{Conclusions}

(1) The solar space method (SS) is based on the concept of spatial energy productivity and analysis of ecosystems processes. Its foundational methodology is the integration of process-based emergy analysis into spatial-based ecological footprint analysis. So the SS can help us to understand the mechanisms of energy or mass processes of ecosystems appropriation by human activities such as production, consumption, discharge and reuse of wastes, spatial trade among different regions and so on. In addition, the SS is also very promising in learning or realizing process-pattern-based dynamics of ecosystems appropriation, and resultantly widens the scope of applicability of ecosystems appropriation analysis.

(2) As shown in the above analysis, annual per capita ecosystems appropriation, absolute and relative ecological deficits by SS were bigger than that by EF, being fairly close to actual situation. The SS has a solid foundation of bio-physical flux analysis and explicit contexts of ecosystems. It is helpful to solve methodological problems of ecosystems appropriation in reflecting the characteristics of multi-scales, non-linearity, discontinuity and uncertainty of ecosystems appropriation dynamics, and to finally enhance the predictability of ecosystems appropriation approach. Furthermore, The SS presents a possible opportunity to improve our understanding of the dependence of ecosystems' carrying capacity on temporal-spatial scales, and to explore the measure of ecosystems' carrying capacity.

(3) Drawn from the case study of Yangzhou city. As a relatively higher industrialized city in Eastern China, most types of ecological space in Yangzhou city were in a state of deficit. Especially, the deficit of solar space was at a high level, but freshwater areas and built-up areas were in a state of surplus. The relative deficit of earth surface space and solar space were respectively as high as $3.68 \%$ and $154.86 \%$. The development of Yangzhou strongly depended on ecosystems outside of the city, which would become a potential limitation for its future's sustainable development. On the other hand, freshwater areas became a unique ecological advantage for maintaining and enhancing the city's ecological carrying capacity. At a longterm point of view, it is necessary for the city to steadily increase the ability of managing the temporal-spatial dynamics of ecosystems appropriation to match the natural capacity of ecosystems services, and to further develop a self-persistent model of ecosystems appropriation, finally realize an ecological society of low-deficit risk.

(4) The results from the current research are still preliminary, and further research needing to be considered includes: (i) the 
improvement of parameters of equivalent factors for various types of earth surface spaces based on actual observable or experimental data other than some assumptions suggested by EF; (ii) further analysis on the temporal and spatial dynamics of ecosystems appropriation based on the results of the current study so as to understand or explore their dynamic characteristics; (iii) analysis of the driving mechanisms of dynamics of ecosystems appropriation by modeling techniques. All these research will improve our understanding of the complexity of ecosystems appropriation.

\section{Acknowledgements}

This research was financially supported by the National Natural Science Foundation of China (70873121; 70573106), the Knowledge Innovation Project of the Chinese Academy of Sciences (KZCX2-YW-324, KZCX2-YW-422), the National Basic Research Program of China (2005CB724206) and the Key Supporting Project of Ministry of Science and Technology of China (2007BAC28B04). This work was also supported by the State Key Laboratory of Urban \& Regional Ecology (SKLURE2008-1-01), Chinese Academy of Sciences. Many thanks were given to Prof. Bai-lian Li for his constructive suggestions to improve the paper.

\section{Appendix A}

(1) Solar space coefficient: solar radiant power is $3.8268 \mathrm{E}+26 \mathrm{j} / \mathrm{s}$, thus, the annual available amount of solar radiant energy is $1.20682 \mathrm{E}+25 \mathrm{Gj}$, and the total surface area of the sun is 6.08717E+14 ha (cited from Geography Dictionary, Shanghai Dictionary Publishing House, 1983), so solar space coefficien$\mathrm{t}=$ annual solar radiation/surface area of the sun $=1.9826 \mathrm{E}+10 \mathrm{Gj} /$ Sa-ha.

(2) Transformity of global bio-productive areas (TGB): TGB = emergy amount of a unit area of global average bio-productive areas (Gj/Ga-ha) divided by solar space coefficient ( $\mathrm{Gj} / \mathrm{Sa}-\mathrm{ha}$ ) $=1.3424 \mathrm{E}+07 \mathrm{Gj} / \mathrm{Ga}-\mathrm{ha} / 1.9826 \mathrm{E}+10 \mathrm{Gj} / \mathrm{Sa}-\mathrm{ha} /$ $\mathrm{y}=6.7713 \mathrm{E}-04$ Sa-ha/Ga-ha.

In this calculation, the emergy amount of global average bioproductive areas = energy transformation rate of primary bioproducts $\times$ emergy transformity of primary bio-products $\times$ annual global yield of primary bio-products of global average bioproductive areas $=1.2133 \mathrm{E}+07$ (biomass) joules $/$ (biomass) kilogram $\times 2.2167 \mathrm{E}+05$ (solar energy)joules/(earth biomass)joule $\times 4.9915 \mathrm{E}+03 / 1,000,000,000 \mathrm{~kg} / \mathrm{ha}=1.3424 \mathrm{E}+07 \mathrm{Gj} / \mathrm{Ga}-\mathrm{ha}$.

\section{Appendix B}

(1) Equivalent factor of ESS (EFS): EFS = average solar radiation intensity of ESS $(\mathrm{Gj} / \mathrm{Ga}-\mathrm{ha}) /$ solar space coefficient $(\mathrm{Gj} / \mathrm{Sa}-\mathrm{ha})$ $=5.5056 \mathrm{E}+04 \mathrm{Gj} / \mathrm{Ga}-\mathrm{ha} / 1.9826 \mathrm{E}+10 \mathrm{Gj} / \mathrm{Sa}-\mathrm{ha}=2.7770 \mathrm{E}-06 \mathrm{Sa}-$ ha/Ga-ha.

In the above calculation, the average solar radiation intensity of the ESS $(\mathrm{Gj} / \mathrm{Ga}-\mathrm{ha})=$ total solar radiation energy which may arrive in the outer layer of the earth atmosphere $\times$ the arrival rate/total surface area of the earth $=5.5$ $\mathrm{E}+15 \mathrm{Gj} \times 0.51 / 5.0948 \mathrm{E}+10 \mathrm{ha}=5.5056 \mathrm{E}+04 \mathrm{Gj} / \mathrm{Ga}-\mathrm{ha}$. The arrival rate refers to the ratio of the actual amount that arrives on the land from the outer layer of the earth atmosphere to the total amount which reaches the outer atmospheric layer of the earth from the sun since the solar energy intensity gradually decreased due to some atmosphere effects (like absorption, reflection, etc.) when it passes through the atmosphere. This value is estimated to be $51 \%$.
(2) In Yangzhou, the solar radiation intensity of the local land surface is $4.7291 \mathrm{E}+04 \mathrm{Gj} / \mathrm{ha}$ in a year.

(3) The transformities for embodied energy (emergy) calculation in any energy or products are cited from Odum (1996) and Ulgiati et al. (1994), which are not listed again in this paper.

(4) The remaining coefficient of local solar radiation $f=1-r, r$ is the average percentage of availability of solar energy for local ecosystems on the land surface. The average availability of solar energy for local ecosystems refers to the percentage of solar radiation that could be absorbed and used by local ecosystems in a given length of time. In our research, the value of $r$ is equal to $10 \%$.

(5) In the early research literatures, EF did not involve the appropriation of freshwater, the followed-up researches of EF gradually counted appropriation of some freshwater aquatic products, but neglected water supply.

\section{References}

Ayres, R.U., 2000. Commentary on the utility of the ecological footprint concept. Ecological Economics 32, 347-349.

Anand, M., Li, B.L., 2001. Spatiotemporal dynamics in a transition zone: patchiness, scale, and an emergent property. Community Ecology 2 (2), 161-169.

Bicknell, K.B., Ba1l, R.J., Cullen, R., Bigsby, H.R., 1998. New methodology for the ecological footprint with an application to the New Zealand economy. Ecological Economics 27, 149-160.

Folke, C., Jansson, A., Larsson, J., Costanza, R., 1997. Ecosystem appropriation by cities. Ambio 26, 167-172.

Ferng, J.J., 2001. Using composition of land multiplier to estimate ecological footprints associated with production activity. Ecological Economics 37, $159-172$.

Haberl, H., 1997. Human appropriation of net primary production as an environmental indicator: implications for sustainable development. Ambio 26, $143-$ 146.

Haberl, H., Erb, K.H., Krauusmann, F., 2001. How to calculate and interpret ecological footprints for long period of time: the case of Austria 1926-1995. Ecological Economics 38, 25-45.

Haberl, H., Wackernagel, M., Krausmann, F., Erb, K.H.K.H., Monfreda, C., 2004 Ecological footprints and human appropriation of net primary production: a comparison. Land Use Policy 21, 279-288.

Jansson, A.M., Zucchetto, J., 1978. Energy, economic and ecological relationships for Gotland, Sweden: a regional systems study. Ecological Bulletins, vol. 28. Swedish Natural Science Research Council.

Jansson, A., Folke, C., Rockström, J., Gordon, L., 1999. Linking freshwater flows and ecosystem services appropriated by people: the case of the Baltic Sea drainage basin. Ecosystems 2, 351-366

Li, B.L., Gorshkov, V.G., Makarieva, M., 2004. Energy partitioning between different organisms and ecosystem stability. Ecology 85, 1811-1813.

Lenzen, M., Murray, S.A., 2001. A modified ecological footprint method and its application to Australia. Ecological Economics 37, 229-255.

Moffatt, I., 2000. Ecological footprint and sustainable development. Ecological Economics 32, 359-362.

Makarieva, M., Gorshkov, V.G., Li, B.L., Chown, S.L., Reich, P.B., Gavrilov, V.M. 2008a. Mean mass-specific metabolic rates are strikingly similar across life's major domains: evidence for life's metabolic optimum. PNAS 105, 16994 16999.

Makarieva, M., Gorshkov, V.G., Li, B.L., 2008b. Energy budget of the biosphere and civilization: rethinking environmental security of global renewable and nonrenewable resources. Ecological Complexity 5, 281-288.

Makarieva, M., Gorshkov, V.G., Li, B.L., Chown, S.L., 2006. Size- and temperatureindependence of minimum life-supporting metabolic rates. Functional Ecology 20, 83-96.

Makarieva, M., Gorshkov, V.G., Li, B.L., 2005. Why do population density and inverse home range scale differently with body size? Implications for ecosystem stability. Ecological Complexity 2, 259-271.

Makarieva, M., Gorshkov, V.G., Li, B.L., 2004. Body size, energy consumption and allometric scaling: a new dimension in the diversity-stability debate. Ecological Complexity 1, 139-175.

Odum, E.P., 1975. Ecology: The Link Between the Natural and Social Sciences. HoltSaunders, New York.

Odum, E.P., 1989. Ecology and Our Endangered Life-support Systems. Sinauer Associates, Sunderland.

Odum, H.T., 1996. Environmental Accounting-EMERGY and Environmental Decision Making. John Wiley \& Sons, Inc., New York.

Postel, S.L., Daily, G.C., Ehrlich, P.R., 1996. Human appropriation of renewable fresh water. Science 271, 785-788.

The People's Government of Yangzhou City, 1998. Master Plan of Land Uses in Yangzhou City of 1997-2010.

Rees, W.E., 2000. Eco-footprint analysis: merits and brickbats. Ecological Economics $32,371-374$ 
Simmons, C., Lewis, K., 2000. Two feet - two approaches: a component-based model of ecological footprinting. Ecological Economics 32 (3), 375-380.

Ulgiati, S., Odum, H.T., Bastianoni, S., 1994. Emergy use, environment loading and sustainability: an emergy analysis of Italy. Ecological Modeling 73, 215-268.

Van den Bergh, J.C.J.M., Verbruggen, H., 1999. Spatial sustainability, trade and indicators: an evaluation of the 'Ecological Footprint'. Ecological Economics $29,61-72$.

Vitousek, P.M., Ehrlich, P.R., Ehrlich, A.H., Matson, P.A., 1986. Human appropriation of the products of photosynthesis. BioScience $36,368-373$.

Vitousek, P.M., Mooney, H.A., Lubchenco, J., Milillo, J.M., 1997. Human domination of earth's ecosystems. Science 277, 494-499.

Wackernagel, M., Rees, W.E., 1996. Our Ecological Footprint-Reducing Human Impact on the Earth. New Society Publishers, Gabriola Island, Philadelphia.
Wackernagel, M., Lewan, L., Borgström-Hansson, C., 1999a. Evaluating the use of natural capital with the ecological footprint, Applications in Sweden and subregions. Ambio 28, 604-612.

Wackernagel, M., Onisto, L., Bello, P., Linares, A.C., Falfan, I.S.L., Garcýa, J.M., Guerrero, A.I.S., Gueerrero, M.G.S., 1999b. National natural capital accounting with the ecological footprint concept. Ecological Economics 29, 375390.

Wackernagel, M., Monfreda, C., Moran, D., Wermer, P., Goldfinger, S., Deumling, D., Murray, M., 2005. National footprint and biocapacity accounts 2005: the underlying calculation method. Global footprint network.

Yangzhou Statistic Bureau, 2001. Statistical Yearbook of Yangzhou 2001.

Yangzhou Environmental Protection Bureau, 2001. Environmental Yearbook of Yangzhou City 2001. 